\title{
Stress Distribution in a Cohesionless Backfill Poured in a Silo
}

\author{
$\mathrm{Li} \mathrm{Li}^{1,2, *}$, Jonathan D. Aubertin ${ }^{1}$ and Jean-Sébastien Dubé ${ }^{1}$
}

\author{
${ }^{1}$ Department of Construction Engineering, École de Technologie Supérieure (ETS), Montreal, Quebec, H3C 1 K3 \\ Canada \\ ${ }^{2}$ Research Institute on Mines and the Environment (RIME), Department of Civil, Geological and Mining Engineering, \\ École Polytechnique de Montréal, C.P. 6079 succursale Centre-ville, Montreal, Quebec, H3C 3A7 Canada
}

\begin{abstract}
The field of infrastructure rehabilitation and development requires a better understanding of soil-structure interactions. The interaction behaviour between soil and structures has mostly been investigated through theoretical and/or numerical analysis. This paper presents a series of experiments performed on an intermediate-scale physical model made of an instrumented silo. In contrast to most reported laboratory tests, both the horizontal and vertical stresses were monitored during backfilling operations realised by wild pouring. Drop tests were performed to investigate the density variation with respect to the drop (or falling) height of the soil, which were introduced in the pressure interpretation. The results showed that horizontal stress in the direction parallel to the pouring plane is larger than that perpendicular to the pouring plane. Apparently, the vertical stress is well-described using the arching solution by considering the backfill in an active state, whereas the horizontal stress perpendicular to the pouring plane is better described with the arching solution by considering the backfill in an at-rest state. An estimate of the earth pressure coefficients based on the measured vertical and horizontal stresses indicates, however, that the backfill was closer to an at-rest state in the direction perpendicular to the pouring plane, whereas in the direction parallel to the pouring plane, it was in a state between at-rest and passive. These results indicate that it is important to measure both the horizontal and vertical stresses to obtain a whole picture of the state of the backfill. The results showed also that the horizontal stresses can be larger than those calculated by the overburden solution, probably due to dynamic loading by drop mass during the filling operation and stress lock.
\end{abstract}

Keywords: Analytical solution, Arching effect, Backfill, Laboratory tests, Silo, Stress measurement.

\section{INTRODUCTION}

Interaction between soil or backfill and structures is a commonly observed phenomenon in geotechnical engineering $[1,2]$. When a frictional particulate material, such as cereals, grains, cement, or chemical powder, is placed in a confined opening with stiffer walls, it tends to yield and settle under its own weight, whereas the abutment walls tend to hold it in place by shearing stresses along the interfaces between the particulate material and the abutment walls. Part of the load due to the particulate material weight is then transferred from the particulate material to the surrounding walls. The stresses within the particulate material then become smaller than those calculated with the overburden solution. This phenomenon is known as the "arching effect" $[3,4]$.

The broad application of the arching theory in the construction industry is mostly due to the pioneering work of Marston [5], who made use of Janssen's arching theory and introduced an analytical solution for evaluating the load on

\footnotetext{
*Address correspondence to this author at the Research Institute on Mines and the Environment (RIME), Department of Civil, Geological and Mining Engineering, École Polytechnique de Montréal, C.P. 6079 succursale Centre-ville, Montreal, Quebec, H3C 3A7 Canada; Tel: 1-514-340-4711 \#2408; Fax: 1-514-340-4477; E-mail: li.li@ polymtl.ca
}

conduits buried in trenches. Since then, the arching theory has been widely used in stress estimation within backfill placed in municipal trenches [6-8], in powder silos [2, 9$11]$, behind retaining walls [12-14], and in mining stope [15-28]. The occurrence of arching is also a well-known phenomenon in dam cores confined by granular soils [29], around piles driven in soft soils [30], in soft soils above a tunnel [31, 32], and beneath a stockpile [33, 34].

In recent years, a number of new achievements have been reported for improving the stress estimation in backfilled openings (trenches and mining stopes). These include numerical modelling of arching effects [15, 16, 23] and analytical solution developments that take into account the third dimension [17-19, 35], wall inclination [26, 36-39], pore water pressure [21, 22], and non-uniform stress distribution [20, 24]. Although these analytical and numerical solutions constitute useful tools in the design of civil infrastructure and mining backfill, their validity by experimental tests becomes a critical concern.

Experimentations can be conducted in the field or laboratory. Under field conditions, several influencing factors, such as irregular geometry, physical and hydraulic properties evolution in the fill and along the fill-wall interfaces, temperature, displacement of confining walls, dynamic loading due to the passage of vehicles for municipal infrastructures or production blasting in mining stopes, could 
be concurrently involved. This makes the interpretation of experiments a great challenge [2, 25, 27, 40, 41]. In contrast to field tests, laboratory experimentations allow the control and measurement of the main influencing factors. However, most experimental results obtained in the laboratory have been obtained using small scale models with few variations of the experimental conditions, and measurement of only one (horizontal or vertical) stress component. For instance, Take and Valsangkar [13] made use of a box of $254 \mathrm{~mm} \times 150$ $\mathrm{mm} \times 184$ (length $\times$ height $\times$ width) placed in a centrifuge to simulate a $5 \mathrm{~m}$ prototype wall using an acceleration of 35.7 times gravity. Only horizontal stresses were measured. Pirapakaran and Sivakugan [42] investigated the arching effect using one column $15 \mathrm{~cm}$ in diameter to simulate circular stopes and another $15 \mathrm{~cm}$ in width to simulate square stopes, both $90 \mathrm{~cm}$ in height. Only vertical pressures were measured. The backfilling operation of all these experiments was realised by the air pluviation technique to obtain a homogenous backfill $[13,42]$. This does not correspond to field conditions for large silos, municipal trenches, or mining stopes, where backfilling is usually achieved by wild pouring. Recently, Ting et al. [43] performed a series of laboratory tests with a physical model made of a box of approximately $90 \mathrm{~cm} \times 50 \mathrm{~cm} \times 12.4 \mathrm{~cm}$ (length $\times$ height $\times$ width) to simulate an inclined stope. Filling was performed using a funnel with an adjustable opening to control the deposition intensity. An average backfill density was used in their data interpretation without considering the density variation with falling height.
In this paper, a series of laboratory tests performed with a silo $69 \mathrm{~cm}$ in diameter and $190 \mathrm{~cm}$ in height is presented. Compared to most laboratory tests of small scale physical model, this intermediate scale physical model allows performing backfilling tests under more representative field conditions. In contrast to most existing testing procedures, the backfilling operation was realised by wild pouring to imitate the true field backfilling conditions. Both the vertical and horizontal stresses were measured in order to obtain a whole picture of the stress state and an estimate of the backfill state (commonly quantified by an earth pressure coefficient, $K$ ) during the backfilling of the silo. The density variation of the backfill with falling height was measured and taken into account in the interpretation of the results. Comparisons were made between the experimental results and some analytical solutions used for estimating the stresses in backfilled silos. A discussion is followed.

\section{PRESSURE MEASUREMENTS IN A COHESION- LESS SOIL POURED IN A SILO}

\subsection{Physical Model}

The physical model consisted of a stainless steel silo with an internal diameter of $69 \mathrm{~cm}$ and an effective height of 190 $\mathrm{cm}$ from its bottom to top Fig. (1a), and a pressure measurement system Fig. (1b) installed at its bottom Fig. (1c). The pressure measurement system was made of

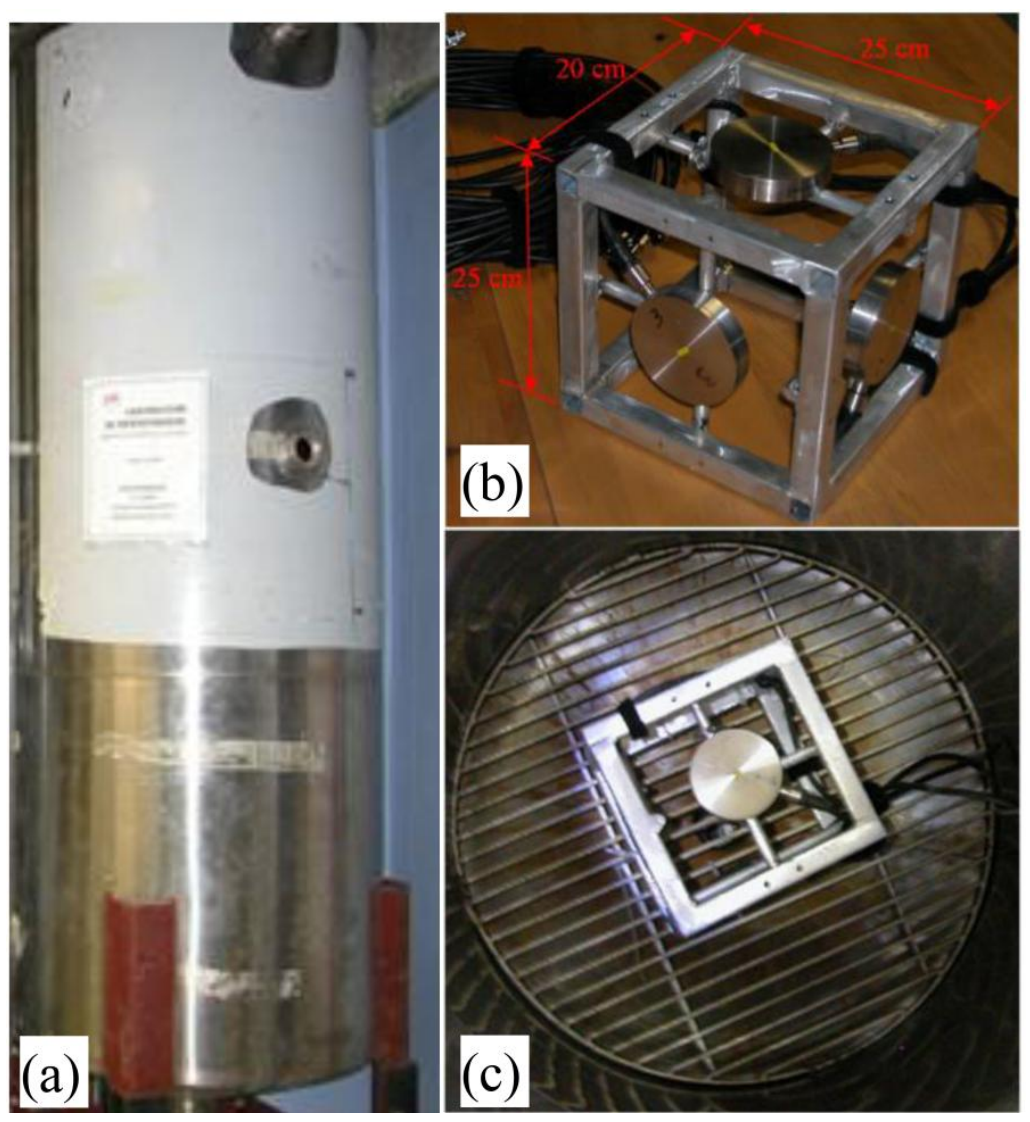

Fig. (1). Physical model used to measure the stresses in a backfilled opening: (a) a silo of $69 \mathrm{~cm}$ in diameter and $190 \mathrm{~cm}$ in height, a pressure measurement system (b) before and (c) after being mounted in the silo. 
three pressure sensors mounted on a metal cube and connected with a computer via a data acquisition card. It was fixed at the bottom of the silo after several calibrations with a water column.

Fig. (2) shows the position of the sensors and the corresponding fill thickness. Sensor 1 was horizontally positioned and measured the vertical pressure. Sensor 2 was positioned vertically with its face toward the pouring position; it measured the horizontal stress in the direction parallel to the pouring plane. Sensor 3 was also positioned vertically with its face parallel to the pouring plane; it measured the horizontal stress in the direction perpendicular to the pouring plane. For a given thickness of backfill, $h_{\mathrm{b}}$, the fill thickness above Sensor 1 is $h_{1}=h_{\mathrm{b}}-28 \mathrm{~cm}$, whereas the fill thickness above Sensors 2 and 3 is $h_{2}=h_{\mathrm{b}}-15.5 \mathrm{~cm}$.

\subsection{Testing Material}

The fill material used here is commercial sand from Bomix ${ }^{\circledR}$. Its grain-size distribution curve is shown in Fig. (3), showing a fine particulates $(\leq 75 \mu \mathrm{m})$ content less than $5 \%$ with a uniformity coefficient $C_{\mathrm{u}}=4.44$ and a coefficient of curvature $C_{\mathrm{c}}=1.03$. It is classified as a poorly graded sand. Direct box shear tests conducted on the sand and on the sand-steel interface gave a fill friction angle $(\phi)$ of $42.9^{\circ}$ and a fill-wall interface friction angle $(\delta)$ of $25.5^{\circ}$, leading to a $\delta$ over $\phi$ ratio of approximately 0.6 , a value slightly smaller than but close to that of the $2 / 3$ commonly assumed in geotechnical engineering [30]. In the loosest state, it has a porosity of approximately $36 \%$ and a dry density of $1596 \mathrm{~kg} / \mathrm{m}^{3}$. When compacted under standard and

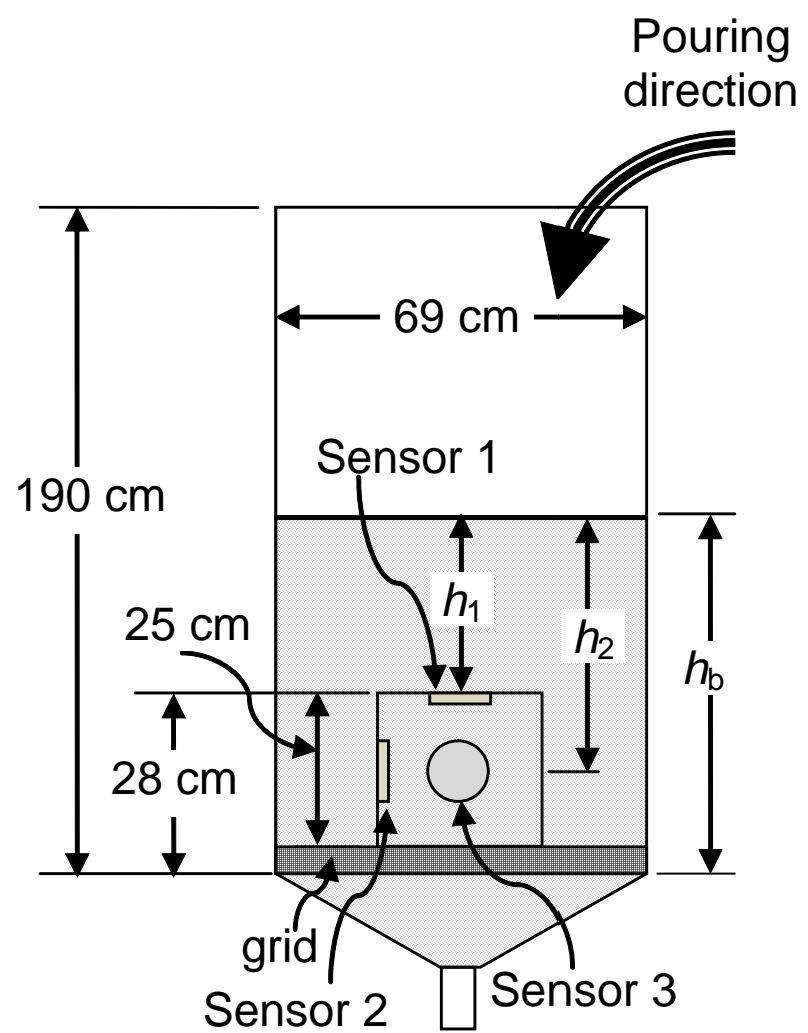

Fig. (2). Location of sensors and fill thickness: $h_{\mathrm{b}}$ is the fill thickness; $h_{1}$ and $h_{2}$ are the fill thicknesses above Sensor 1 and Sensors 2 and 3, respectively.

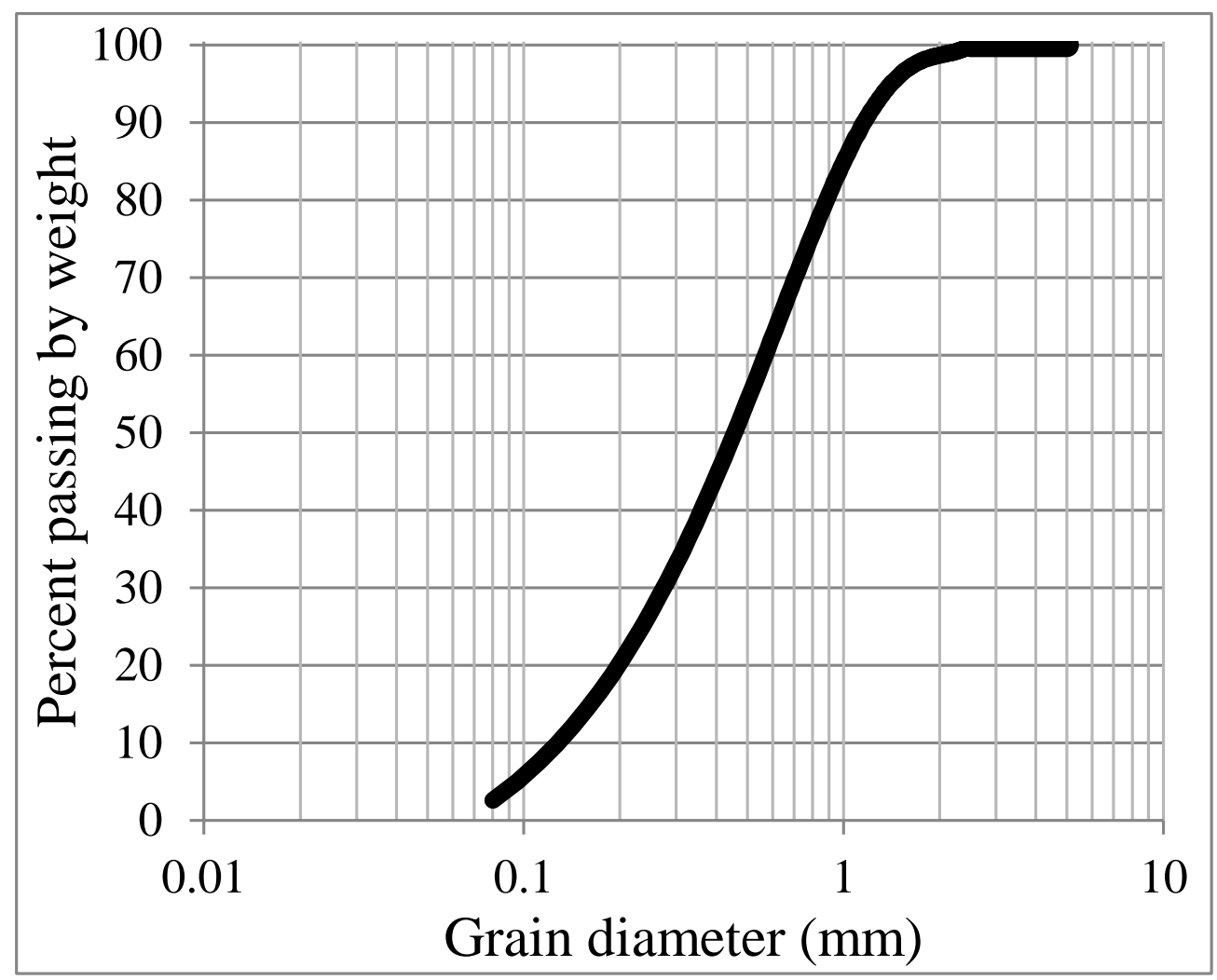

Fig. (3). Grain-size distribution curve of Bomix sand. 
modified Proctor test procedures, it has a dry density of 1805 $\mathrm{kg} / \mathrm{m}^{3}$ and $1860 \mathrm{~kg} / \mathrm{m}^{3}$, respectively.

In most laboratory investigations, a constant density is used to estimate the pressures within a backfilled opening. This could be considered as acceptable if the testing model is small or if the fill material is placed using an air or water pluviation technique with minimal variation of falling height between the pouring and receiving levels [13, 42].

In practice, however, the air or water pluviation technique is rarely applied. Filling is usually achieved by wild pouring deposition. Accordingly, the first backfill layers are compacted during their placement and further compacted during the filling of the later layers, leading to density values higher in lower layers and smaller in the upper layers. This phenomenon, known as density variation with falling (or drop) height, has been investigated by a number of researchers [44-47], who showed that the soil density increases with drop height as long as the drop height is smaller than a critical value beyond which the density becomes insensitive to the variation of drop height.

Fig. (4a) schematically shows the variation of fill thickness with pouring operation. With a given initial falling height $\left(H_{0}\right)$, the drop height $\left(h_{\mathrm{f}}\right)$ decreases with the increase of the fill thickness $h_{\mathrm{b}}$. The following equation is used to describe the variation of the global dry density with an increase of the fill thickness [48]:

$\rho=\rho_{\text {end }}+\left(\rho_{\text {max }}-\rho_{\text {end }}\right)\left\langle 1-\frac{h_{\mathrm{b}}}{H_{0}}\right\rangle^{\lambda}$

Where $\rho$ is the global dry density corresponding to the fill thickness $h_{\mathrm{b}}, \rho_{\max }$ is the maximum dry density of the soil, and $\rho_{\text {end }}$ is the global dry density when the fill thickness $h_{\mathrm{b}}$ is equal to $H_{0}$. Fig. (4b) shows the instrumentation used for measuring the global dry density of the sand with fill thickness. Fig. (4c) presents the global dry density measured as a function of the fill thickness. The tests were performed with an initial drop height $\left(H_{0}\right)$ of $2 \mathrm{~m}$. This drop height was approximately equal to the initial height between the pouring point (somewhat higher than the top of the silo) and the silo's bottom. The experimental results showed that the global density decreased from a maximum value of approximately $1812 \mathrm{~kg} / \mathrm{m}^{3}$ at the beginning of the filling operation to $1689 \mathrm{~kg} / \mathrm{m}^{3}$ at the end of the tests. The maximum value was very close to the dry density of the sand under the standard Proctor compaction procedure. The tests were stopped at a fill thickness of $75 \mathrm{~cm}$ due to a balance capacity limitation. The global density was expected to decrease further if the filling tests had been continued. Fig. (4c) shows that the variation of the measured global dry density was well described by the proposed Eq. (1) using $H_{0}$ $=200 \mathrm{~cm}, \rho_{\max }=1860 \mathrm{~kg} / \mathrm{m}^{3}, \rho_{\mathrm{end}}=1689 \mathrm{~kg} / \mathrm{m}^{3}$, and $\lambda=$ 8.827 .

\subsection{Testing Procedure}

Before the backfilling operation with sand, the pressure measurement system was again calibrated by filling the silo with water. Several days later, when the silo wall became dry after draining the water from the silo, the cone part of the silo was filled with sand $1.5 \mathrm{~cm}$ higher than the grid surface, which was at $3 \mathrm{~cm}$ above the silo's bottom (plane of reference). Thus, the filling operation started with an initial backfill of $4.5 \mathrm{~cm}$ in thickness from the silo's bottom. The backfilling was performed by pouring sand in layers of approximately $10.2 \mathrm{~cm}$ each, followed by a levelling operation between each layer. Thereafter, measurements at several positions (generally one in the centre and three along the perimeter) over the backfill surface were made to obtain an average height between the fill surface and the top of the silo. The fill thickness between the bottom and top of the fill was calculated, corresponding to the measured thickness of the backfill. The horizontal and vertical stresses were measured once the filling operation started.

\subsection{Experimental Results}

A series of experimental tests were performed by considering different filling sequences and conditions. Some typical results are presented below. (a)

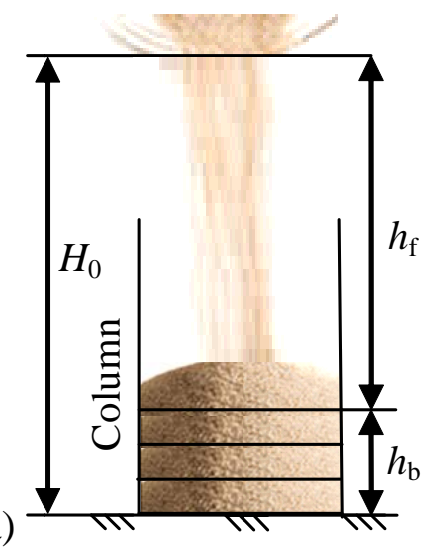

(b)

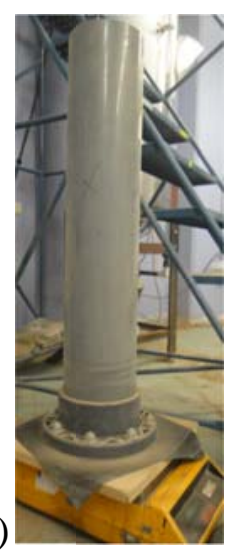

(c)

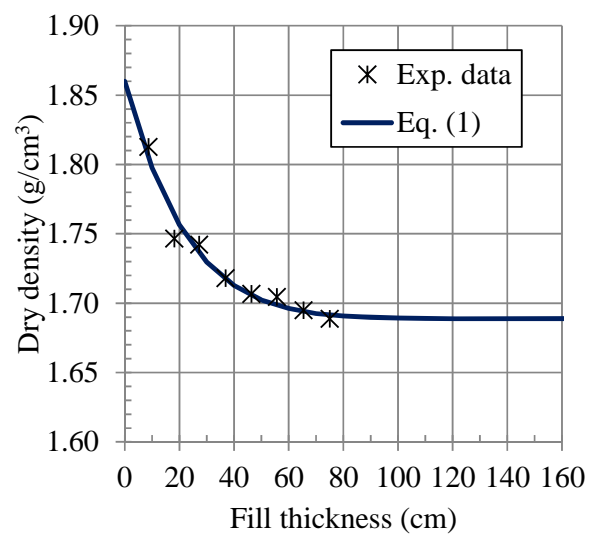

Fig. (4). Global dry density variation with drop height $\left(h_{\mathrm{f}}\right)$ and fill thickness $\left(h_{\mathrm{b}}\right)$ : $(\mathbf{a})$ schematic presentation of the test; $(\mathbf{b})$ column of $20 \mathrm{~cm}$ in diameter and $110 \mathrm{~cm}$ in height used for the sand drop tests; (c) experimental results and description with Eq. (1) using $H_{0}=200 \mathrm{~cm}, \rho_{\max }=1860 \mathrm{~kg} / \mathrm{m}^{3}, \rho_{\text {end }}=1689 \mathrm{~kg} / \mathrm{m}^{3}$, and $\lambda=8.827$. 


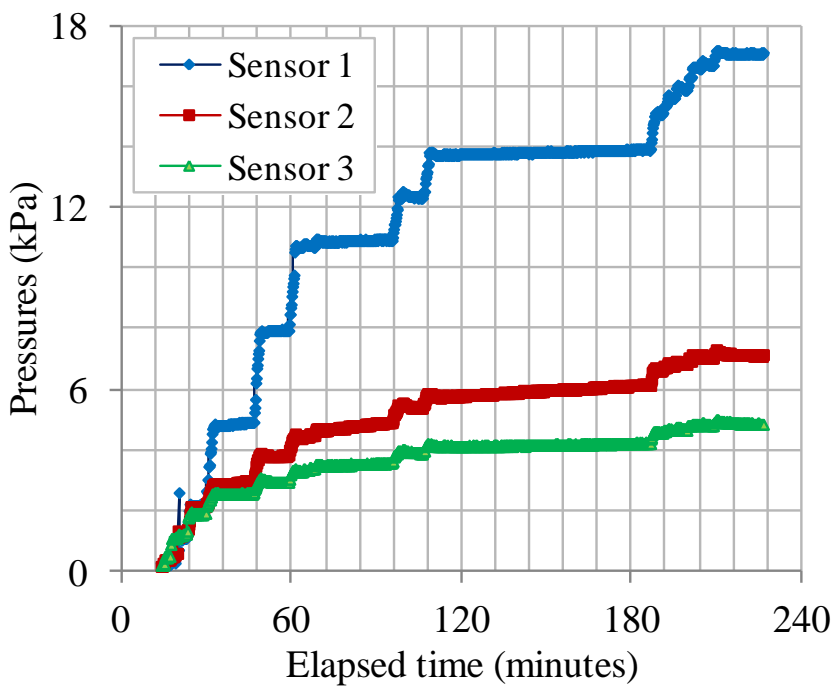

Fig. (5). Pressure variation with filling: Sensor $1=$ vertical stress; Senor $2=$ horizontal stress parallel to the pouring plane; Sensor $3=$ horizontal stress perpendicular to the pouring plane.

Fig. (5) shows the variation of pressures measured during the filling operation. Another filling test was performed, and the results (not shown here) were very close to those shown in Fig. (5), indicating a good reproducibility of the tests. From the figure, we note that the vertical pressure (Sensor 1) was larger than the horizontal pressures (Sensors 2 and 3). We note also that the two vertically positioned sensors behaved differently; Sensor 3, had its face parallel to the pouring plane and showed a horizontal stress smaller than that measured by Sensor 2, which had its face perpendicular to the pouring plane (see Fig. 2). These results indicate that the fill deposition technique influences the state of the backfill and the stress distribution in a backfilled opening. In

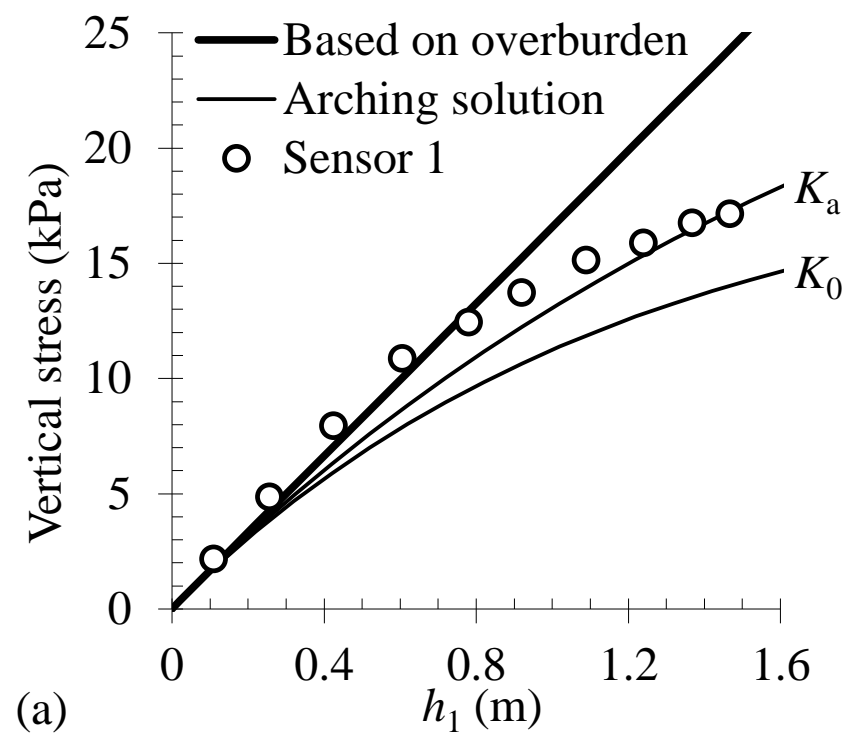

most laboratory tests, an air or water pluviation technique is usually applied to obtain a uniform backfill. The state of the backfill and the resulting horizontal stress distribution are isotropic in the horizontal plane. The experimental results presented here demonstrate that the state of the backfill obtained with a wild pouring operation can become pouring direction dependent. Along the pouring direction (plane), the backfill was more compacted than in the direction perpendicular to the pouring plane. Accordingly, the horizontal stress was larger in the direction parallel to the pouring plane than in the direction perpendicular to the pouring plane.

Fig. (6) shows the variation of the measured vertical Fig. (6a) and horizontal Fig. (6b) stresses with fill thickness. In the figure, the stresses calculated with an arching solution proposed by Cowin [9] are also plotted:

$$
\begin{aligned}
& \sigma_{\mathrm{v}}=\frac{\gamma D}{4 K \tan \delta}\left\{1-\exp \left(-4 K h D^{-1} \tan \delta\right)\right\} \\
& \sigma_{\mathrm{h}}=K \sigma_{\mathrm{v}}
\end{aligned}
$$

Where $\sigma_{\mathrm{v}}$ and $\sigma_{\mathrm{h}}$ are the vertical and horizontal normal stresses in the backfill at a depth, $h$, respectively. $\gamma(=\rho g ; g$ is the gravity accelerator) is the unit weight of the backfill whose variation with the fill thickness, $h_{\mathrm{b}}$, was taken into account using Eq. (1). $\delta$ is the friction angle along the fillwall interface. $D$ is the internal diameter of the silo, and $K$ is the earth pressure coefficient of the cohesionless material. For a vertical backfilled opening, the value of $K$ is usually considered to be close to Rankine's active earth pressure coefficient, $K_{\mathrm{a}}$ :

$$
K=K_{\mathrm{a}}=\tan ^{2}\left(45^{\circ}-\frac{\phi}{2}\right)
$$

Where $\phi$ is the friction angle of the backfill. Numerical simulations of vertical backfilled openings performed by $\mathrm{Li}$

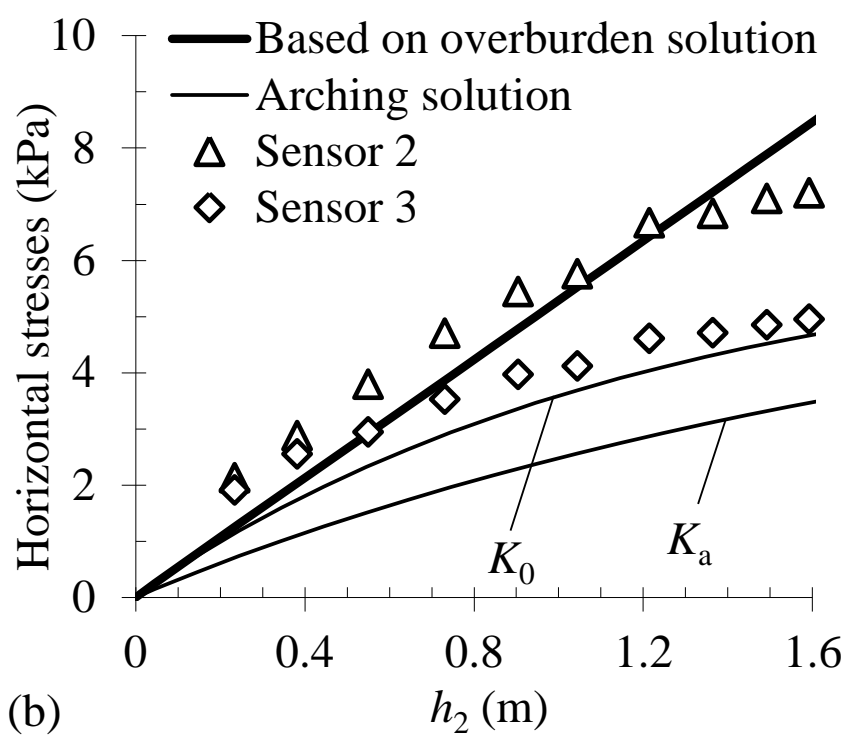

Fig. (6). Vertical (a) and horizontal (b) stresses measured and calculated with the analytical solutions after taking into account the density variation with drop height by using Eq. (1) with $H_{0}=2 \mathrm{~m}, \rho_{\max }=1860 \mathrm{~kg} / \mathrm{m}^{3}, \rho_{\text {end }}=1689 \mathrm{~kg} / \mathrm{m}^{3}$, and $\lambda=8.827$. Other parameters used in the analytical solutions were: $D=69 \mathrm{~cm}, \phi=42.9^{\circ}$, and $\delta=25.5^{\circ}$. 
et al. [16] showed that the expected value of the earth pressure coefficient $K$ may actually vary between $K_{\mathrm{a}}$ and $K_{0}$. $K_{0}$ is the at rest earth pressure coefficient [49]:

$K=K_{0}=1-\sin \phi$

From Fig. (6), we observe that both the vertical $\left(\sigma_{\mathrm{v}}\right)$ and horizontal $\left(\sigma_{\mathrm{h}}\right)$ stresses increased nonlinearly with the fill thickness. This indicated the occurrence of the arching effect, which was further confirmed by the deviation of the measured vertical [Fig. (6a); Sensor $1=\sigma_{\mathrm{v}}$ ] and horizontal [Fig. (6b); Sensor 2 and $3=\sigma_{\mathrm{h}}$ ] stresses below the linear stress distribution based on the overburden solution near the end of the filling tests.

For the vertical stress component [Fig. (6a)], the measured values followed the stress distribution predicted by the overburden solution, as long as the fill thickness was smaller than approximately $0.8 \mathrm{~m}$. Beyond that thickness, the measured vertical stress deviated from the overburden solution and tended to approach the results predicted by the arching analytical solution using the active earth pressure coefficient, $K_{\mathrm{a}}$.

For the horizontal stresses [Fig. (6b)], when the backfill thickness was small $\left(h_{2}<0.25 \mathrm{~cm}\right)$, the two components parallel and perpendicular to the pouring plane were almost identical. Their difference increased with fill thickness. The component in the direction perpendicular to the pouring plane (measured by Sensor 3) exceeded not only the values predicted by the arching solution but also those predicted by the overburden solution when the fill thickness was smaller than $0.5 \mathrm{~m}$. The same phenomenon was observed for the component parallel to the pouring plane (measured by Sensor 2) when the fill thickness was less than $1.2 \mathrm{~m}$. This aspect will further be addressed in the Discussion. In general, the horizontal stress perpendicular to the pouring plane [Fig. (6b); Sensor 3] was similar and close to the arching analytical solution using an at-rest earth pressure coefficient, $K_{0}$. However, the component parallel to the pouring plane [Fig. (6b); Sensor 2] was much higher than those predicted with the arching solution, even if the backfill was considered to be in an at-rest state (with the earth pressure coefficient $K_{0}$ ).

\section{DISCUSSION}

In this study, an intermediate scale physical model using an instrumented silo was presented. Backfilling was realised by wild pouring. This manner of backfilling and the ensuing experimental results are more representative of the field conditions where wild pouring is usually practiced in the powder (large silos), civil (trenches), and mining (stopes) industries. The results show that the tests are reproducible and the measurement systems are viable. However, the interaction behaviour between a structure and a wild poured backfill was much more complicated than that between the structure and a backfill obtained by applying an air or water pluviation technique. In the former case, fill anisotropy, property changes with the thickness and dynamic effects were involved.

The nonlinear variation of the three measured stresses with fill thickness indicated the occurrence of the arching effect. Apparently, the vertical stress was better described by the arching solution using an active earth pressure coefficient, $K_{\mathrm{a}}$, whereas the horizontal stress in the direction perpendicular to the pouring plane was better described by the arching solution using an at-rest earth pressure coefficient, $K_{0}$. However, an estimate of the earth pressure coefficients Fig. (7b) based on curve fitting technique to the measured vertical and horizontal stresses Fig. (7a) indicates that the backfill is closer to an at-rest state in the direction perpendicular to the pouring plane (Sensor 3). In the direction parallel to the pouring plane (Sensor 2), the backfill is in a state between at-rest and passive. These results indicate that it is important to measure both the horizontal
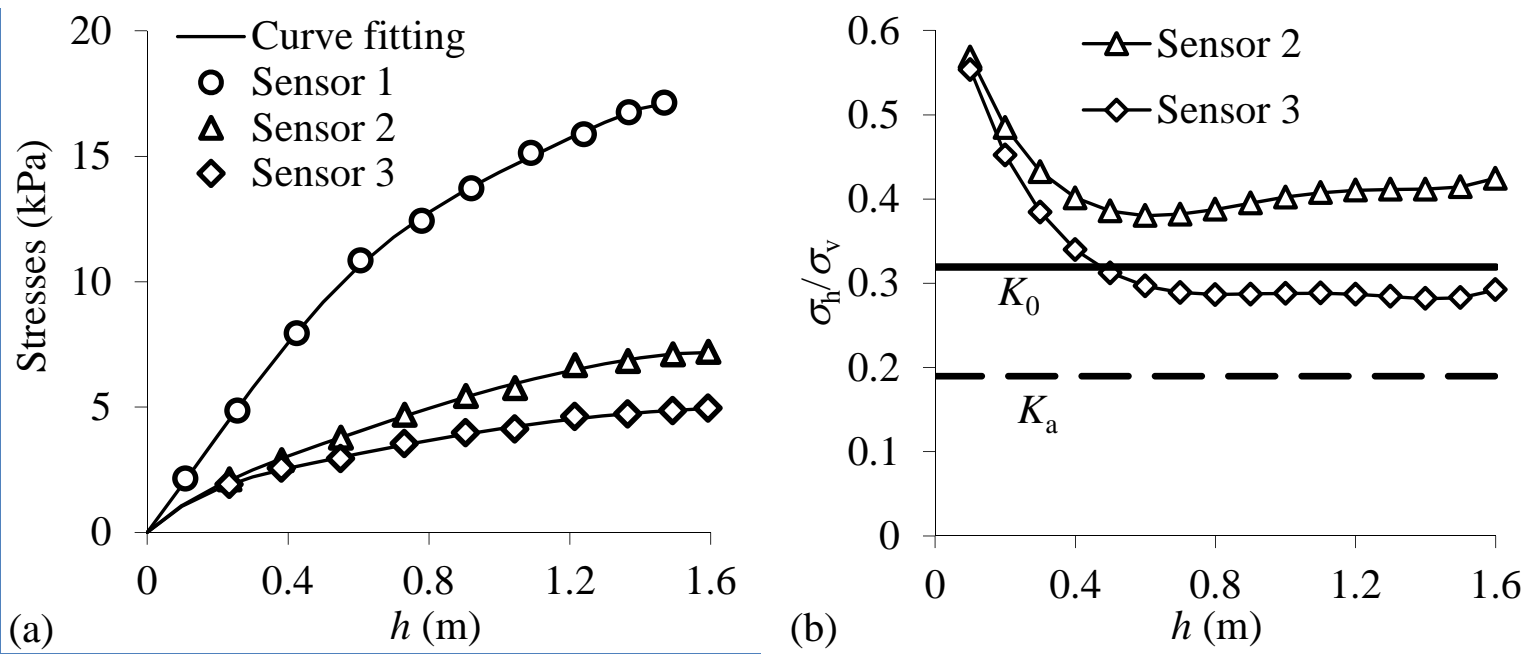

Fig. (7). (a) Description of the variation of measured stresses based on curve fitting technique: Sensor 1 with $\sigma_{\mathrm{v}}=-4.9583 h^{6}+$ $14.527 h^{5}-5.7908 h^{4}-15.455 h^{3}+7.6843 h^{2}+18.355 h$, Sensor 2 with $\sigma_{\mathrm{h}}=-2.6034 h^{6}+14.624 h^{5}-33.129 h^{4}+37.83 h^{3}-$ $23.757 h^{2}+12.811 h$, and Senor 3 with $\sigma_{\mathrm{h}}=-1.5339 h^{6}+10.593 h^{5}-28.681 h^{4}+38.5 h^{3}-27.645 h^{2}+12.903 h$. (b) An estimate of the variation of the earth pressure coefficients with thickness of backfill, $h$. 
and vertical stresses to obtain a whole picture of the state of the backfill. The experimental results also showed that the horizontal stress parallel to the pouring plane was significantly underestimated by the existing arching analytical solution using the at-rest earth pressure coefficient $K_{0}$, indicating that a silo design based on such an analytical solution would be on the non-conservative side. More work is required to fully understand the final true state of the backfill using larger depth-to-diameter ratio silos with more precise pressure measurement system $[50,51]$.

The experimental results revealed that the measured horizontal stresses can exceed the values calculated with the overburden solution, which is considered as the upper bound solution for stress estimation in soils. Similar results have been reported in the case of silos [2], backfilled openings [13], and backfills behind a retaining wall [41]. There is no further explanation given in the literature. In our opinion, this phenomenon is related to the dynamic response of backfilling. Fig. (8) shows a pressure record during the beginning of a backfilling test performed later. Dynamic loading was generated due to the impact of the dropped mass during the pouring operation, leading to a momentary state in which the stress magnitudes were higher than those predicted by the overburden solution. In the vertical direction, the excess stresses due to the transient impact can mostly be released due to the presence of a free surface on top of the backfill. The final vertical stress would be close to that predicted by the overburden solution. In the horizontal directions, full release of the excess stress is impossible due to the absence of a free face; part of the stress would be locked by the rigid confining wall of the structure, resulting in final horizontal stress higher than predicted by the overburden solution. When the thickness of the backfill is large, the arching effect prevails due to reduction in the backfill dropping height and dynamic loading.

\section{CONCLUSION}

In this study, experimental results obtained using an intermediate-scale physical model were reported. Backfilling operations were realised by wild pouring. Both the

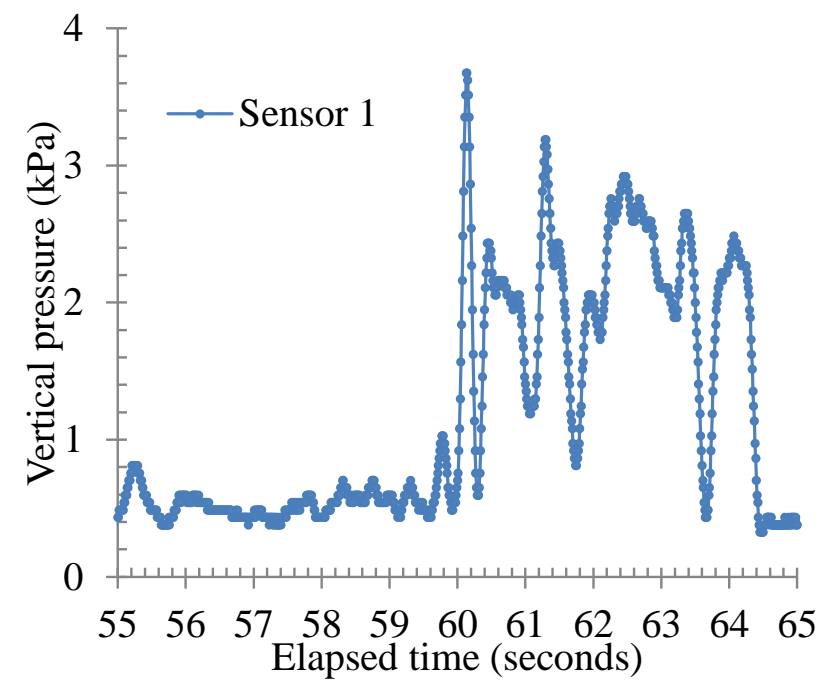

Fig. (8). Variation of the vertical pressure at the beginning of the pouring operation of a test. horizontal and vertical stresses were measured. The density variation with drop (or falling) height of the soil was also measured and was introduced in the pressure interpretation. The results indicate that the response of a backfill realised by wild pouring is significantly different from that of a backfill obtained by air or water pluviation. The backfill by wild pouring may have anisotropic behaviour in the horizontal plane due to the impact of dynamic loading by drop mass, resulting in horizontal stress that is higher in the direction parallel to the pouring plane than in the direction perpendicular to the pouring plane. The results also showed that the horizontal stresses may exceed the values predicted by the upper bound overburden solution, probably due to the combined effects of the dynamic loading generated by the impact of the drop masses during filling and the restriction of the confining wall of the structure. Here, the vertical stress was well-described by the arching solution using the active earth pressure coefficient $K_{\mathrm{a}}$, whereas the horizontal stress perpendicular to the pouring plane was relatively welldescribed by the arching solution using the at-rest earth pressure coefficient $K_{0}$. Regarding the horizontal stress parallel to the pouring plane, its variation tendency followed the stress distribution predicted by the arching solution using the at-rest earth pressure coefficient $K_{0}$, but its magnitude was much higher than predicted by the latter solution.

\section{CONFLICT OF INTEREST}

The authors confirm that this article content has no conflicts of interest.

\section{ACKNOWLEDGEMENTS}

The authors acknowledge the financial support from École de Technologie Supérieure (ETS), Polytechnique Montreal, the NSERC (RGPIN), and the Canada Research Chair. Experimental tests were realised with the assistance provided by C. Kéchichian, H.-H. Vu, F. Avendano, J. Lescelleur and J. Mauricio. Support from G. Lefebvre, F. Brissette, O. Chaallal, S. Bélisle, C. Lavoie, L. Paquin, M. Ouellet and B. Vachon) is also acknowledged. Anonymous reviewers are gratefully acknowledged for their comments that helped significantly to improve the quality of the paper.

\section{REFERENCES}

[1] K. Harrop-Williams, "Arch in soil arching", ASCE J. Geotech. Eng., vol. 115, no. 3, pp. 415-419, 1989.

[2] G. E. Blight, Assessing loads on silos and other bulk storage structures: Research applied to practice. Taylor \& Francis/Balkema, The Netherlands, 2006.

[3] H. A. Janssen, "Versuche über Getreidedruck in Silozellen", Zeitschrift Verein Ingenieure, vol. 39, pp. 1045-1049, 1895.

[4] M. Sperl, "Experiments on corn pressure in silo cells - translation and comment of Janssen's paper from 1895", Granular Matter, vol. 8, pp. 59-65, 2006.

[5] Marston, "The theory of external loads on closed conduits in the light of latest experiments", Bulletin No 96, Iowa Engineering Experiment Station, Ames, Iowa, 1930.

[6] R. L. Handy, "The arch in soil arching", ASCE J. Geotech. Eng., vol. 111, no. 3, pp. 302-318, 1985.

[7] M. G. Spangler and R. L. Handy, Soil Engineering. Harper and Row, New York, 1984.

[8] W. R. Whidden, Buried flexible steel pipe: Design and structure analysis, ASCE Manuals and Reports on Engineering Practice No $119,2009$.

[9] S. C. Cowin, "The theory of static loads in bins", J. Appl. Mech., vol. 44, pp. 409-412, 1977. 
[10] Drescher, Analytical methods in bin-load analysis. Elsevier, New York, 1991.

[11] Y. M. Cheng, Z.N. Liu, W.D. Song and S.K. Au "Laboratory test and particle flow simulation of silos problem with nonhomogeneous materials", ASCE J. Geotech. Geoenviron. Eng., vol. 135, no. 11, pp. 1754-1761, 2009.

[12] Y. Z. Wang, "Distribution of earth pressure on retaining wall", Géotechnology, vol. 50, no. 1, pp. 83-88, 2000.

[13] W. A. Take and A. J. Valsangkar, "Earth pressures on unyielding retaining walls of narrow backfill width", Can. Geotech. J., vol. 38, pp. 1220-1230, 2001.

[14] K. H. Paik and R. Salgado, "Estimation of active earth pressure against rigid retaining walls considering arching effects", Géotechnology., vol. 53, no. 7, pp. 643-653, 2003.

[15] M. Aubertin, L. Li, S. Arnoldi, T. Belem, B. Bussière, M. Benzaazoua, and R. Simon, "Interaction between backfill and rock mass in narrow stopes", Soil and Rock America 2003, Verlag Glückauf Essen (VGE), Essen, vol. 1, pp. 1157-1164, 2003.

[16] L. Li, M. Aubertin, R. Simon, B. Bussière, and T. Belem, "Modeling arching effects in narrow backfilled stopes with FLAC", FLAC and Numerical Modeling in Geomechanics - 2003, A.A Balkema, Lisse, pp. 211-219, 2003.

[17] L. Li, M. Aubertin, and T. Belem, "Formulation of a three dimensional analytical solution to evaluate stresses in backfilled vertical narrow openings", Can. Geotech. J., vol. 42, no. 6, pp. 1705-1717, 2005.

[18] L. Li, M. Aubertin, and T. Belem, "Erratum: Formulation of a three dimensional analytical solution to evaluate stresses in backfilled vertical narrow openings", Can. Geotech. J., vol. 43, pp. 338-339, 2005.

[19] L. Li, M. Aubertin, and T. Belem, "Development of a 3D analytical solution to evaluate stresses in backfilled vertical openings", Technical report EPM-RT-2005-04, École Polytechnique de Montréal, 2005.

[20] L. Li, and M. Aubertin, "An improved analytical solution to estimate the stress state in sub-vertical backfilled stopes", Can. Geotech. J., vol. 45, no. 10, pp. 1487-1496, 2008.

[21] L. Li, and M. Aubertin, "Influence of water pressure on the stress state in stopes with cohesionless backfill", Geotech. Geol. Eng. vol. 27, no. 1, pp. 1-11, 2009.

[22] L. Li, and M. Aubertin, "A three-dimensional analysis of the total and effective normal stresses in submerged backfilled stopes", Geotech. Geol. Eng., vol. 27, no. 4, pp. 559-569, 2009.

[23] L. Li, and M. Aubertin, "Numerical investigation of the stress state in inclined backfilled stopes" ASCE Int. J. Geomech., vol. 9, no. 2, pp. 52-62, 2009

[24] L. Li, and M. Aubertin, "An analytical solution for the nonlinear distribution of effective and total stresses in vertical backfilled stopes. Geomech. Geoeng., vol. 5, no. 4, pp. 237-245, 2010.

[25] M.W. Grabinsky, "Keynote address - In situ monitoring for groundtruthing paste backfill designs", Proc 13th Int. Seminar on Paste and Thickened Tailings. Australian Centre for Geomechanics, pp. 85-98, 2010.

[26] C.H. Ting, S.K. Shukla, and N. Sivakugan, "Arching in soils applied to inclined mine stopes", ASCE Int. J. Geomech., vol. 11, no. 1, pp. 29-35, 2011.

[27] B.D. Thompson, W.F. Bawden, and M.W. Grabinsky, "In situ measurements of cemented paste backfill at the Cayeli Mine", Can. Geotech. J., vol. 49, pp. 755-772, 2012.

[28] N. Sivakugan, K. Rankine, J. Lovisa, and W. Hall, "Flow rate computations in hydraulic fill mine stopes", Indian Geotech. J., vol. 43, no. 3, pp. 195-202, 2013.

[29] Kutzner, Earth and rockfill dams: Principles of design and construction. Balkema, Rotterdam, 1997.

[30] CGS, Canadian foundation engineering manual. Can. Geotech. Society, BiTech Publisher, 2006.
[31] Ladanyi, and B. Hoyaux, "A study of the trap-door problem in a granular mass", Can. Geotech. J., vol. 6, no. 1, pp. 1-14, 1969.

[32] G.R. Iglesia, H.H. Einstein, and R.V. Whitman, "Determination of vertical loading on underground structures based on an arching evolution concept", Geo-Engineering for Underground Facilities, C. Fernandez, and R.A. Bauer, Eds. Geo-Institute of ASCE, pp. 495-506, 1999.

[33] R.L. Michalowski, and N. Park, "Admissible stress fields and arching in piles of sand", Geotechnology, vol. 54, no. 8, pp. 529538, 2004.

[34] J. Ai, J.F. Chen, J.M. Rotter, and J.Y. Ooi, "Numerical and experimental studies of the base pressures beneath stockpiles" Granular Matter, vol. 13, no. 2, pp. 133-141, 2011.

[35] K. Pirapakaran, and N. Sivakugan, "Arching within hydraulic fill stopes”, Geotech. Geol. Eng., vol. 25, no. 1, pp. 25-35, 2007.

[36] S.K. Shukla, J.G. Loughran, and N. Sivakugan, "Stress within a cohesionless granular fill in a storage vessel with sloping walls during initial static loading", Powder Technology, vol. 192, pp. 389-393, 2009

[37] S.K. Shukla, S. Gaurav, and N. Sivakugan, "A simplified extension of the conventional theory of arching in soils", Int. J. Geotech. Eng., vol. 3, no. 3, pp. 353-359, 2009.

[38] L. Li, J.-S. Dubé, and M. Aubertin, "An extension of Marston's solution for the stresses in backfilled trenches with inclined walls", Geotech. Geol. Eng., vol. 31, pp. 1027-1039, 2013.

[39] L. Li, J.-S. Dubé, and Z. Zangeneh-Madar, "Estimation of total and effective stresses in trenches with inclined walls", Int. J. Geotech. Eng., vol. 6, no. 4, pp. 525-538, 2012.

[40] T. Belem, A. Harvey, R. Simon, and M. Aubertin, "Measurement and prediction of internal stresses in an underground opening during its filling with cemented fill", Proc. 5th Int. Symp. on Ground support in Min. Underground Construction, E. Villaescusa, and Y. Potvin, Eds. Taylor \& Francis, pp. 619-630, 2004.

[41] T.S. O'Neal, and D.J. Hagerty, "Earth pressures in confined cohesionless backfill against tall rigid walls - a case history", Can. Geotech. J., vol. 48, pp. 1188-1197, 2011.

[42] K. Pirapakaran, and N. Sivakugan, "A laboratory model to study arching within a hydraulic fill stope", Geotech. Test J., vol. 30, no. 6, pp. 1-8, 2007.

[43] C.H. Ting, N. Sivakugan, and S.K. Shukla, "Laboratory simulation of the stresses within inclined stopes", Geotech. Test J., vol. 35, no. 2, pp. 1-15, 2012.

[44] Y.P. Vaid, and D. Negussey, "Relative density of pluviated sand samples", Soils Found, vol. 24, no. 2, pp. 101-105, 1984.

[45] N.S. Rad, and M.T. Tumay, "Factors affecting sand specimen preparation by raining", Geotech. Test J., vol. 10, no. 1, pp. 31-37, 1987.

[46] D.C.F. Lo Presti, R. Berardi, S. Pedroni, and V. Crippa, "A new travelling sand pluviator to reconstitute specimens of well-graded silty sands", Geotech. Test J., vol. 16, no. 1, pp. 18-26, 1993.

[47] Cresswell, M.E. Barton, and R. Brown, "Determining the maximum density of sands by pluviation", Geotech. Test J., vol. 22, no. 4, pp. 324-328, 1999.

[48] L. Li, M. Aubertin, R. Simon, D. Deng, and D. Labrie, "Influence of scale on the uniaxial compressive strength of brittle rock", Rock Mechanics: Meeting Society's Challenges and Demands, E. Eberhardt, D. Stead, and T. Morrison, Eds. Taylor \& Francis, vol. 1, pp. 785-792, 2007.

[49] J. Jaky, "Pressure in silos", Proc. 2nd Int. Conf. Soil Mech. Foundation Eng., Balkema, Rotterdam, vol. 1, pp. 103-107, 1948.

[50] M. Talesnick, "Measuring soil contact pressure on a solid boundary and quantifying soil arching", Geotech Test J., vol. 28, no. 2, pp. 171-179, 2005.

[51] M. Talesnick, "Measuring soil pressure within a soil mass", Can. Geotech. J., vol. 50, pp. 716-722, 2013. 